\section{Validação do conteúdo de um instrumento para avaliação da prontidão do prematuro para início da alimentação oral}

\section{Content validation as a tool for evaluating oral feeding readiness in preterm babies}

Cristina I. Fujinaga 1

Carmen G. S. Scochi 2

Claudia B. Santos 3

Nelma E. Zamberlan 4

Adriana M. Leite 5

1 Universidade Estadual do Centro-Oeste. UNICENTRO. PR 153 Km 7. Irati, PR, Brasil. CEP: 84500-000.

E-mail: cifujinaga@irati.unicentro.br

2-5 Escola de Enfermagem de Ribeirão Preto. Universidade de São Paulo. Ribeirão Preto, SP, Brasil.

\section{Abstract}

Objectives: to produce and validate the content and appearance of a tool for evaluating the readiness of preterm infants to begin the transition from gastric to oral feeding.

Methods: for the validation of the tool and accompanying instructions, the authors established a minimum percentage agreement of $85 \%$ among the 15 peers who participated in the study, all of them speech therapists with broad experience in the area of neonatology.

Results: the validated tool and accompanying instructions contained the following items: corrected gestational age, state of behavioral organization (state of consciousness, overall posture and overall muscle tone), oral posture (lips and tongue), oral reflexes (rooting, sucking, biting and gagging) and non-nutritive sucking (tongue movements, cupped tongue configuration, jaw movements, sucking force, sucking pause, maintaining the rhythm sucking and pause, maintaining an alert state and signs of stress).

Conclusions: the tool and accompanying instructions aim to systematize the evaluation of preterm infants, beginning with the transition from gastric to oral feeding. Clinical validation is necessary before they can be used in neonatal wards.

Key words Infant, Premature, Behavior, Sucking

\section{Resumo}

Objetivos: elaborar e validar o conteúdo e a aparência de um instrumento de avaliação da prontidão do prematuro em iniciar a transição da alimentação gástrica para via oral.

Métodos: para validação do conteúdo do instrumento e seu respectivo guia instrucional, estabeleceu-se um percentual mínimo de concordância de $85 \%$ entre os "juizes", fonoaudiólogos com experiência na área de neonatologia.

Resultados: obteve-se concordância acima de $85 \%$ nos itens avaliados. O instrumento e guia instrucional validados ficaram constituidos dos seguintes itens: idade corrigida, estado de organização comportamental (estado de consciência, postura e tônus global), postura oral (lábios e língua), reflexos orais (procura, sucção, mordida e vômito) e sucção não-nutritiva (movimentação e canolamento de língua, movimentação da mandíbula, força de sucção, sucções por pausa, manutenção do ritmo de sucção por pausa e do estado alerta e sinais de estresse).

Conclusões: o instrumento e guia instrucional objetivam e sistematizam a avaliação do bebê prematuro iniciar a transição da alimentação gástrica para via oral. Para o uso em unidades neonatais, há necessidade de sua validação clínica.

Palavras-chave Prematuro, Comportamento, Sucção 


\section{Introdução}

Nos últimos anos, vem crescendo no Brasil, o número de unidades de cuidado intensivo neonatais, permitindo um atendimento mais adequado aos recém-nascidos pré-termo e de baixo peso ao nascer. ${ }^{1}$

A incorporação de tecnologia sofisticada e de alta complexidade tem contribuído para a diminuição da mortalidade neonatal, mas ainda existe um longo caminho em direção à redução da morbidade e qualidade de vida dessas crianças. $\mathrm{O}$ enfoque da assistência vem se transformando e direcionando o cuidar não somente para a sobrevivência dos bebês, mas tem-se dirigido para a assistência integral, humanizada e preventiva, dentro de uma perspectiva global, visando à qualidade de vida dessas crianças. 1

Nessa assistência, observa-se uma tendência em oferecer o leite materno o mais precocemente possível, no sentido de atender às necessidades nutricionais e melhorar as relações mãe-bebê. ${ }^{2}$

Na última década, a atuação clínica e preventiva junto aos recém-nascidos em berçário de risco e unidade de terapia intensiva neonatal evoluiu, não só pelo desenvolvimento da tecnologia de cuidado a esses bebês, como também pelo reconhecimento de profissionais médicos, de enfermagem e do auxílio efetivo de profissionais da área de fonoaudiologia. 3

Com relação à idade corrigida, idade pós-natal e peso, há uma grande variação individual que interfere na habilidade da criança prematura se alimentar por via oral. Pesquisadores relatam que 32 semanas de gestação é o período mais curto que se pode esperar de um bebê para desenvolver a habilidade de sugar e deglutir, a qual é precedida pela habilidade de engasgar, que reflexivamente evita a aspiração. 3-6

A avaliação da sucção não-nutritiva pode ser utilizada como um indicativo de maturidade para iniciar a transição para alimentação oral, em conjunto com outros aspectos do comportamento global do bebê, como idade gestacional, postura e tônus global e estado comportamental. ${ }^{7}$

No entanto, percebe-se na prática clínica que os critérios para iniciar a transição da alimentação gástrica para via oral são o peso e a idade gestacional. Nesse processo os profissionais de saúde têm considerado tais parâmetros de forma isolada, sem realizar uma avaliação das condições gerais do bebê, de seu desenvolvimento neuropsicomotor e de sua habilidade motora oral. Além disso, essa transição geralmente é realizada através do uso de "chucas" ou mamadeira.8-13 O sucesso da alimentação oral depende de muitas variáveis: idade gestacional, peso, estabilidade fisiológica e clínica, tônus muscular, ganho ponderal, experiência de sucção prévia, organização comportamental do bebê, controle do ambiente e da postura. ${ }^{14}$

As escalas de avaliação da alimentação em prematuros estão baseadas na observação descritiva, tendo como referência a "Neonatal Oral-Motor Assessment Scale" (NOMAS). 15-17 Trata-se de um instrumento constituído por 13 características de movimentos de mandíbula e de língua, divididos em categorias: normal, desorganizado e disfuncional. A avaliação da sucção não-nutritiva é realizada durante dois minutos e a nutritiva em cinco minutos. ${ }^{16}$

A NOMAS foi aplicada em 40 bebês com idades de 35 a 40 semanas, com o objetivo de estabelecer a confiabilidade do instrumento, revisar a escala de acordo com o grau de confiança alcançado e melhorar a qualidade e descrição dos padrões de desorganização e disfunção da sucção no período neonatal. O instrumento alcançou um nível de concordância de $80 \%$ entre os observadores, mas outras características como a consistência interna, reprodutiblidade e aplicação clínica do instrumento necessitavam ser avaliadas. 16

Observa-se uma dificuldade por parte da fonoaudiologia em sistematizar uma avaliação objetiva do comportamento de sucção do bebê e seu desempenho na transição para a via oral. Os serviços têm se apoiado numa avaliação na qual se descreve o comportamento de sucção, baseado na observação da sucção não-nutritiva, o que não é um indicador preciso para o início dessa transição. 17-19

Estão descritos na literatura nacional alguns protocolos de avaliação da sucção do bebê prematuro. ${ }^{17-19}$ No entanto, nenhum desses protocolos foi validado, e nem se dispõe de um guia instrucional para sua aplicação.

O objetivo deste estudo foi a elaboração e validação, do conteúdo e aparência, de um instrumento de avaliação da prontidão do bebê prematuro iniciar a alimentação por via oral.

\section{Métodos}

Trata-se de um estudo de validação que tem seu foco no desenvolvimento, avaliação e aperfeiçoamento de instrumentos e de estratégias metodológicas. 20

O projeto de pesquisa foi aprovado pelo Comitê de Ética da Escola de Enfermagem de Ribeirão Preto da Universidade de São Paulo.

$\mathrm{O}$ instrumento para avaliar a prontidão do prematuro para início da alimentação oral foi elaborado para bebês clinicamente estáveis, não contem- 
plando aqueles com deformidades faciais, distúrbios respiratórios, cardiovasculares, gastrintestinais e neurológicos ou portadores de síndromes que impeçam ou dificultem a alimentação oral. Caso o prematuro apresente-se chorando, o mesmo não deverá ser avaliado, uma vez que o choro influencia negativamente o seu desempenho.

O processo de validação de um teste inicia-se com a formulação de definições detalhadas dos itens, derivadas da teoria ou literatura, de pesquisa anterior ou da observação sistemática e análise de um comportamento. 20 Assim, tendo por base uma revisão bibliográfica, ${ }^{3-19}$ foram considerados os comportamentos relevantes do prematuro para iniciar a transição da alimentação gástrica para via oral referentes a aspectos globais e motor-oral, resultando na elaboração de 17 itens a serem considerados na construção de um instrumento de avaliação. Tais itens se referiram aos sinais clínicos do estado de organização comportamental do prematuro (estado de consciência, postura e tônus global, postura de lábios e língua, reflexo de procura, sucção, mordida e vômito) e do seu desempenho no teste da sucção não-nutritiva (movimentação e canolamento da língua, movimentação da mandíbula, força e ritmo de sucção, manutenção do ritmo, manutenção do estado alerta e sinais de estresse). Para cada item do instrumento foram previstas três opções de manifestação clínica e desempenho do prematuro, às quais se atribuiram escores de 0 a 2 , sendo o maior escore observado naquelas respostas consideradas adequadas para se iniciar a transição da alimentação.

Participaram da validação do conteúdo e aparência do protocolo 15 "juízes", ou seja, fonoaudiólogos que atuam em neonatologia na assistência à alimentação de prematuros. Tal grupo deveria julgar a abrangência dos itens selecionados, assim como, a representatividade e pertinência de cada um deles em relação às características a serem avaliadas, além do conteúdo das definições operacionais. A amostra foi obtida por conveniência e os dados foram coletados no segundo semestre de 2001, por meio de envio de correspondência. $O$ critério de inclusão foi que os "juízes" possuíssem pelo menos três anos de experiência em neonatologia. Todos os "juízes" eram do sexo feminino e possuíam tempo de atuação profissional de 3 a 16 anos, com média de 8,6 anos. Os "juízes" validaram também o guia instrucional, com as características definidoras de cada item, bem como a relevância e os escores atribuídos aos mesmos, sendo considerado um percentual de concordância maior ou igual a $85 \%$. Considerou-se validado cada item do instrumento, e suas respectivas definições operacionais, quando a concordância entre os "juízes" foi maior ou igual a $85 \%$, percentual este superior aos utilizados em estudos de validação. ${ }^{21-22}$

Para tanto foi elaborado um questionário $21-22$ dividido em duas partes: a primeira parte continha informações sobre os fonoaudiólogos, objetivando caracterizá-los quanto ao local de trabalho e tempo de atuação em neonatologia; a segunda abrangeu a avaliação desses profissionais quanto à forma $\mathrm{e}$ conteúdo do instrumento (validação de aparência e de conteúdo), bem como as sugestões para aprimorálo.

O questionário continha cinco questões fechadas. Três questões referiram-se à validação de aparência (agrupamento correto e claro dos itens e coerência teórico-prática) e outras duas para julgamento de conteúdo do instrumento (adequação dos escores e atendimento à finalidade do instrumento). No final de cada questão reservou-se um espaço para que os "juízes" justificassem suas respostas ou emitissem sugestões.

Com relação ao guia instrucional, esse continha os conceitos e descrição de cada descritor, itens que compunham o instrumento. A porcentagem de concordância entre os "juízes" refere-se ao conteúdo da descrição de cada item do instrumento, assim como das possíveis respostas do bebê.

\section{Resultados}

A validação foi realizada em duas etapas, visto que na primeira avaliação alguns itens não atingiram a concordância de $85 \%$, sendo necessário um segundo processo de validação.

Após a devolução dos questionários, analisaramse as respostas dos "juízes" de forma quantitativa, anotando suas sugestões.

$\mathrm{Na}$ primeira etapa de validação, cinco itens do instrumento e suas respectivas definições operacionais não atingiram a meta proposta de $85 \%$ de concordância entre os "juízes" (postura de língua, reflexo de procura e de mordida, movimentação de mandíbula e manutenção do ritmo de sucção por pausa). Tais itens foram reformulados, conforme as sugestões enviadas pelos "juízes". Itens como postura global, reflexo de vômito, movimentação da língua e força de sucção, apesar de terem atingido índice de concordância superior a $85 \%$, também sofreram reformulações, pois foram consideradas pertinentes algumas observações dos "juízes". Além disso, decidiu-se alterar o termo "ritmo de sucção" para "sucções por pausa". 
Tabela 1

Índices de concordância obtidos entre os "juízes" na primeira e segunda etapas de validação da aparência e conteúdo de um instrumento de avaliação da prontidão do prematuro iniciar alimentação oral e guia instrucional.

\begin{tabular}{|c|c|c|}
\hline Itens avaliados & $\begin{array}{l}\text { Primeira etapa (\%) } \\
n=15\end{array}$ & $\begin{array}{c}\text { Segunda etapa }(\%) \\
n=14\end{array}$ \\
\hline \multicolumn{3}{|l|}{ Instrumento } \\
\hline Agrupamento claro e correto dos itens & 87,0 & - \\
\hline Coerência entre teoria e prática & 93,0 & - \\
\hline Adequação dos escores atribuídos a cada item & 87,0 & - \\
\hline Atendimento à finalidade proposta & 100,0 & - \\
\hline \multicolumn{3}{|l|}{ Guia instrucional } \\
\hline Idade corrigida & - & 93,0 \\
\hline \multicolumn{3}{|l|}{ Estado de organização comportamental } \\
\hline Estado de consciência & 87,0 & - \\
\hline Postura global & $93,0^{*}$ & 100,0 \\
\hline Tônus global & 93,0 & - \\
\hline \multicolumn{3}{|l|}{ Postura oral } \\
\hline Postura de lábios & 93,0 & - \\
\hline Postura de língua & 74,0 & 86,0 \\
\hline \multicolumn{3}{|l|}{ Reflexos orais } \\
\hline Reflexo de procura & 80,0 & 100,0 \\
\hline Reflexo de sucção & 100,0 & - \\
\hline Reflexo de mordida & 74,0 & 93,0 \\
\hline Reflexo de vômito & $87,0 *$ & 93,0 \\
\hline \multicolumn{3}{|l|}{ Sucção não-nutritiva } \\
\hline Movimentação da língua & $87,0 *$ & 93,0 \\
\hline Canolamento da língua & 100,0 & - \\
\hline Movimentação da mandíbula & 74,0 & 93,0 \\
\hline Força de sucção & $97,0 *$ & 93,0 \\
\hline Sucções por pausa & 97,0 & - \\
\hline Manutenção do ritmo sucções por pausa & 80,0 & 100,0 \\
\hline Manutenção do estado de alerta & 100,0 & - \\
\hline Sinais de estresse & 100,0 & \\
\hline
\end{tabular}

* Itens reformulados, apesar do índice de concordância maior que $85 \%$ na primeira etapa.

Quando questionados se os itens da avaliação estavam agrupados de forma clara e correta, $87 \%$ dos "juízes" aprovaram o instrumento, entretanto, foram acatadas as sugestões daqueles que não concordaram, considerando a pertinência das mesmas.

Dois "juízes" sugeriram que o protocolo fosse reformulado, no sentido de torná-lo mais didático. Dessa forma, o instrumento foi dividido em uma primeira parte, contendo dados de identificação (nome, data de nascimento, idade, tipo de alimentação), e a segunda, com as seguintes categorias: idade corrigida, estado de organização comportamental (estado de consciência, postura e tônus global), postura oral (lábios e língua), reflexos orais (procura, sucção, mordida e vômito) e sucção nãonutritiva (movimentação e canolamento de língua, movimentação de mandíbula, força de sucção, sucções por pausa, manutenção do ritmo sucções por pausa e do estado de alerta e sinais de estresse).

Em relação à coerência entre teoria e prática, obteve-se 93\% de concordância entre os "juízes". A atribuição dos escores nas respostas do bebê apresentou concordância de $87 \%$, e, neste caso, as sugestões enviadas não foram acatadas. Dois "juízes" argumentaram que deveria se atribuir maior escore (2) ao estado comportamental "sono profundo", pois acreditavam que o bebê necessita permanecer nesse estado para desenvolver sua maturação. No entanto, durante a alimentação, o sono profundo dificulta a sucção eficiente; $4,8,15$ sendo assim não se reformulou a definição.

Ao serem questionados se o instrumento serviria de indicador para o início da transição da alimen- 
Instrumento de avaliação da prontidão do prematuro para início da alimentação oral.

\section{Identificação}

Nome:

Data:

Idade pós-natal:

Alimentação: ( ) S.N.G.

DN:

Idade corrigida:

( ) S.O.G. Vol:
No Pront:

Horário:

Idade gestacional:

SNG = Sonda nasogástrica; SOG = Sonda orogástrica

\section{Idade corrigida}

(2) maior ou igual a 34 semanas

(1)entre 32 a 34 semanas

(0)menor ou igual a 32 semanas

\section{Estado de organização comportamental}

$\begin{array}{llll}\text { Estado de consciência } & (2) \text { alerta } & (1) \text { sono leve } & (0) \text { sono profundo } \\ \text { Postura global } & (2) \text { flexão } & (1) \text { semiflexão } & (0) \text { extensão } \\ \text { Tônus global } & \text { (2) normotonia } & (0) \text { hipertonia } & (0) \text { hipotonia }\end{array}$

\begin{tabular}{llll}
\hline $\begin{array}{l}\text { Postura de lábios } \\
\text { Postura de língua }\end{array}$ & $\begin{array}{l}\text { (2) vedados } \\
\text { (2) plana }\end{array}$ & (1) entreabertos & (0) abertos \\
Reflexos orais & & (0) retraída \\
Reflexo de procura & (2) forte & (1) fraco & (0) ausente \\
Reflexo de sucção & (2) forte & (1) fraco & (0) ausente \\
Reflexo de mordida & (2) presente & (1) presente exacerbado & (0) ausente \\
Reflexo de vômito & (2) presente & (1) presente anteriorizado & $(0)$ ausente
\end{tabular}

Sucção não-nutritiva*

\begin{tabular}{|c|c|c|c|}
\hline Movimentação da língua & (2) adequada & (1) alterada & (0) ausente \\
\hline Canolamento de língua & (2) presente & (0) ausente & \\
\hline Movimentação de mandíbula & (2) adequada & (1) alterada & (0) ausente \\
\hline Força de sucção & (2) forte & (1) fraca & (0) ausente \\
\hline Sucções por pausa & (2) $5 a 8 s / p$ & $(1)>8 / p$ & $(0)<5 s / p$ \\
\hline Manutenção do ritmo & (2) rítmico & (1) arrítmico & (0) ausente \\
\hline Manutenção do estado alerta & (2) sim & (1) parcial & (0) não \\
\hline Sinais de estresse & (2) ausente & (1) até 3 & (0) mais de 3 \\
\hline Variação de tônus & ( ) ausente & ( ) presente & \\
\hline Variação de postura & ( ) ausente & ( ) presente & \\
\hline Variação de coloração da pele & ( ) ausente & ( ) presente & \\
\hline Batimento de asa nasal & ( ) ausente & ( ) presente & \\
\hline Tiragem & ( ) ausente & ( ) presente & \\
\hline Apnéia & ( ) ausente & ( ) presente & \\
\hline Acúmulo de saliva & ( ) ausente & ( ) presente & \\
\hline $\begin{array}{l}\text { Tremores de língua ou } \\
\text { mandíbula }\end{array}$ & ( ) ausente & ( ) presente & \\
\hline Soluço & ( ) ausente & ( ) presente & \\
\hline Choro & ( ) ausente & ( ) presente & \\
\hline
\end{tabular}

*A duração do teste deverá ser de 1 minuto

Escore:

Escore máximo: 36 
Anexo 2

Guia Instrucional: instrumento de avaliação da prontidão do prematuro para início da alimentação oral.

\section{Idade corrigida*}

Menor ou igual a 32 semanas.**

Entre 32 a 34 semanas.**

Maior que 34 semanas.**

* Idade corrigida: é a idade gestacional (Ballard) somada à idade pós-natal.

* * Parâmetros definidos tendo por base os autores Lemons, Lemons6 e Palmer.16

\section{Estado de organização comportamental}

\section{Estado de consciência}

Alerta: olhos abertos e brilhantes, responsivo à estimulação, com alguma atividade espontânea.

Sono leve: olhos abrem e fecham, olhar confuso e sem brilho, demora a responder à estimulação, com atividade espontânea variada.

Sono profundo: olhos fechados, não-responsivo à estimulação; a atividade motora é nula.

Postura global

Flexão: flexão de membros superiores e inferiores e posição do pescoço em linha mediana em relação ao tronco.

Semi-flexão: flexão de membros inferiores e posição do pescoço em linha mediana em relação ao tronco.

Extensão: extensão de membros superiores, inferiores e do pescoço em relação ao tronco.

Tônus global

Normotonia: leve resistência à movimentação passiva de flexão e extensão, sendo ligeiramente maior nesta última.

Hipertonia: resistência aumentada à movimentação passiva de flexão e extensão.

Hipotonia: resistência diminuída à movimentação passiva de flexão e extensão.

\section{Postura oral}

Postura de lábios

Vedados: lábio superior e inferior justapostos.

Entreabertos: lábio superior e inferior parcialmente separados.

Abertos: lábio inferior e superior totalmente separados.

Postura de língua

Plana: língua plana, posicionada dentro da cavidade oral, com ponta arredondada.

Elevada: ponta da língua em posição elevada, pressionando o palato.

Retraída: língua em posição de retração na cavidade oral.

Protruída: língua em posição de protrusão na cavidade oral, estando sobreposta aos lábios.

\section{Reflexos orais}

Reflexo de procura

Forte: mediante o estímulo dos quatro pontos cardeais na região perioral, procura imediatamente a região estimulada, direcionando a cabeça ao estímulo e abrindo a boca.

Fraco: mediante o estímulo dos quatro pontos cardeais na região perioral procura lentamente a região estimulada, direcionando ou não a cabeça ao estímulo e/ou com abertura parcial da boca.

Ausente: ausência da resposta.

\section{Reflexo de sucção}

Forte: suga prontamente a própria mão ou o dedo enluvado do avaliador.

Fraco: leva um tempo para iniciar a sucção da própria mão ou o dedo do avaliador.

Ausente: ausência da resposta.

Reflexo de mordida

Presente: responde ao estímulo do dedo do examinador no rolete gengival da cavidade oral, com trancamento da mandíbula, seguido de relaxamento.

Presente exacerbado: responde ao estímulo do dedo do examinador no rolete gengival da cavidade oral, mantendo o trancamento de mandíbula.

Ausente: ausência de respostas.

Reflexo de vômito

Presente: responde com náuseas e/ou vômito ao estímulo da introdução do dedo do avaliador ao atingir a região médio-posterior da língua.

Presente anteriorizado: responde com náuseas ou vômito ao estímulo da introdução do dedo do avaliador já ao atingir a região anterior da língua.

Ausente: ausência de resposta. 
Guia Instrucional: instrumento de avaliação da prontidão do prematuro para início da alimentação oral.

\section{Sucção não-nutritiva}

Movimentação da língua

Adequada: movimento ântero-posterior e coordenado da língua diante do estímulo intra-oral.

Alterada: movimento ou póstero-anterior e incoordenado diante do estímulo intraoral.

Ausente: ausência de movimentação.

Canolamento da língua

Presente: elevação das bordas laterais e presença de sulco na região central da língua.

Ausente: ausência de resposta.

Movimentação de mandíbula

Adequada: reduzida excursão da mandíbula, com movimentação rítmica e suave.

Alterada: ampla excursão da mandíbula e/ou com movimentação arrítmica e/ou trancamento da mesma.

Ausente: ausência de movimentação.

Força de sucção

Forte: forte compressão contra o palato e pressão negativa intraoral* encontrando resistência à retirada do dedo do avaliador da cavidade oral.

Fraca: fraca compressão contra o palato e pressão negativa intraoral* encontrando pouca ou nenhuma resistência à retirada do dedo do avaliador da cavidade oral.

Ausente: ausência de resposta.

Sucções por pausa***

De cinco a oito sucções por pausa respiratória.

Acima de oito sucções por pausa respiratória.

Menos de cinco sucções por pausa respiratória.

*** Para classificar este parâmetro deve-se utilizar a média obtida em três grupos de sucção/pausa.

Manutenção do ritmo de sucção por pausa****

Rítmico: mantém o número de sucções por pausa previsto em um mesmo intervalo (menor que cinco, entre cinco a oito ou maior que oito sucções por pausa).

Arrítmico: altera o número de sucções por pausa entre os intervalos (menor que cinco, entre cinco a oito ou maior que oito sucções por pausa).

Ausente: ausência de sucção.

**** Para classificar este parâmetro deve-se utilizar o número de sucções/pausa obtido em três grupos de sucção/pausa e verificar se ocorreu variação deste número entre os intervalos previstos.

Manutenção do estado alerta

Sim: mantém-se alerta o tempo todo do teste da sucção não-nutritiva.

Parcial: mantém-se alerta apenas no início ou no final do teste da sucção não-nutritiva.

Não: não se mantém alerta durante o teste da sucção não-nutritiva.

Sinais de estresse

Ausente: ausência de sinais de estresse.

Até três sinais de estresse.

Mais de três sinais de estresse.

Os sinais de estresse a serem observados durante a avaliação são:

Variação de tônus

Variação de postura

Variação da coloração da pele

Batimento de asa nasal

Tiragem

Dispnéia

Acúmulo de saliva

Tremores de língua e ou mandíbula

Soluço

Choro 
tação gástrica para a via oral, houve concordância de todos os "juízes", porém três deles sugeriram que se considerasse a maturidade do bebê, verificada através da idade gestacional corrigida, pois quanto mais maduro, melhor será seu desempenho na alimentação por via oral. Atendendo à sugestão, criou-se uma nova categoria, idade corrigida, e atribuiu-se escores que variaram de 0 a 2 , tendo por base parâmetros estabelecidos na literatura.4,6

Para segunda etapa da validação, foi enviado aos "juízes" o instrumento de avaliação reformulado e o guia instrucional contendo somente as definições operacionais que sofreram reformulações.

Nessa fase, foram enviados 15 questionários e apenas um juiz não o devolveu. Ao se analisar as respostas, percebeu-se que todos os itens obtiveram o índice de concordância acima de $85 \%$.

A Tabela 1 indica os índices de concordância obtidos entre os "juízes" na primeira e segunda etapas de validação da aparência e conteúdo de um instrumento de avaliação da prontidão do prematuro iniciar alimentação oral.

Como resultado desse processo de validação, o instrumento e o respectivo guia instrucional, adquiriram a forma que se segue (Anexos 1 e 2).

\section{Discussão}

Atualmente os serviços neonatais se apóiam no peso do prematuro e numa avaliação na qual se descreve o comportamento de sucção, baseado na observação da sucção não-nutritiva, os quais não se constituem em indicadores precisos e suficientes para a equipe iniciar essa transição. ${ }^{18-20}$ Embora existam na literatura alguns protocolos de avaliação, nenhum desses foi validado, nem apresentam guia instrucional para sua aplicação.3,17-19

A maioria dos "juízes" enfatizou a importância da iniciativa para sistematizar e padronizar a assistência aos bebês, procurando suprimir a subjetividade da avaliação e auxiliar a equipe através da apresentação de um indicador mais preciso para início da transição da alimentação.

Considerando que validade é o grau em que um instrumento realmente mede aquilo que foi concebido para medir, 20 esse instrumento só estará totalmente validado ao ser aplicado na prática clínica, mostrando que realmente possui indicadores precisos acerca da prontidão do bebê prematuro para iniciar a alimentação oral (nota de corte, confiabilidade, sensibilidade, especificidade e valores preditivos). Acredita-se na necessidade de pesquisas futuras para continuidade desse estudo, visando sua validação clínica, etapa que as pesquisadoras já estão desenvolvendo.

Espera-se ainda, ampliar as evidências dessa validação clínica a partir do uso do presente instrumento e guia instrucional nas unidades neonatais, acompanhado de estudos analíticos.

O instrumento de avaliação da prontidão do bebê prematuro iniciar a transição da alimentação gástrica para via oral foi validado em seu conteúdo e aparência, por um grupo de 15 juízes que apresentaram um percentual de concordância igual ou maior do que $85 \%$. A validação clínica, próxima etapa do processo de validação do instrumento, já está sendo desenvolvida pelas pesquisadoras.

\section{Referências}

1. Scochi CGS, Riul MJS, Garcia CFD, Barradas LS, Pileggi SO. Cuidado individualizado ao pequeno prematuro: o ambiente sensorial em unidade de terapia intensiva neonatal. Acta Paul Enferm. 2001; 1: 9-16.

2. Rocha NMN, Martinez FE, Jorge SM. Cup or bottle for preterm infants: effects on oxygen saturation, weigh gain, and breastfeeding. J Hum Lact. 2002; 18: 132-8.

3. Hernandez, AM. Atuação fonoaudiológica com recémnascidos e lactentes disfágicos. In: Hernandez AM, Marchesan, I., editores. Atuação fonoaudiológica em ambiente hospitalar. São Paulo: Revinter; 2001. p. 1-37.

4. Bu'lock F, Woolridge MW, Baum JD. Development of coordination of suckling, swallowing and breathing: ultrasound study of term and preterm infants. Dev Med Child Neurol. 1990; 32: 669-78.

5. Glass RP, Wolf LS. A global perspective on feeding assessment in the neonatal intensive care unit. Am J Occup Ther. 1994; 48: 514-26.
6. Lemons K, Lemons JA. Transition to breast/bottle feedings the premature infant. J Am Coll Nutr. 1996; 15: 126-35.

7. Caetano LC, Fujinaga CI, Scochi CGS. Sucção não-nutritiva em bebês prematuros: estudo bibliográfico. Rev Latinoam Enferm. 2003; 11: 232-6.

8. Siddell EP, Froman RD. A national survey of neonatal intensive-care units: criteria used to determine readiness for oral feedings. J Obstet Gynecol Neonatal Nurs. 1994; 23 : 783-9.

9. Lau C, Alagugurusamy R, Schanler RJ, Smith EO, Shulman RJ. Characterization of the developmental stages of sucking in preterm infants during bottle feeding. Acta Paediatr. 2000; 89: 846-52.

10. Gewolb IH, Vice FL, Schweitzer-Kenney EL, Taciak VL, Bosma JF. Developmental patterns of rhythmic suck and swallow in preterm infants. Dev Med Child Neurol. 2001; 43: 22-7. 
11. Lau C, Kusnierczyk I. Quantitative evaluation of infant's nonnutritive and nutritive sucking. Dysphagia. 2001; 16 : 58-67.

12. Howard CR, Lanphear BP, DeBlieck EA, Lawrence RA. Randomized clinical trial of pacifer use and bottle-feeding or cupfeeding and their effect on breastfeeding. Pediatrics. 2003; 111: 511-8.

13. Lau C, Smith EO, Schanler RJ. Coordenation of suckswallow and swallow respiration in preterm infants. Acta Paediatr. 2003; 92: 721-7.

14. Creger PJ, Browne JV. Developmental interventions for preterm and high-risk infants. Denver: Therapy Skill Builders; s.d.

15. Arvedson JC, Brodsky L. Pediatric swallowing and feeding assessment and development. San Diego: Singular; 1993.

16. Palmer MM. Identification and management of the transitional suck pattern in premature infants. J Perinat Neonat Nur. 1993; 7: 66-75.

17. Xavier C. Avaliação de alimentação de recém-nascidos em fase de hospitalização: escala de avaliação motora oral da Irmandade Santa Casa de Misericórdia de São Paulo. PróFono. 1995; 7: 69-74.

Recebido em 22 de dezembro de 2006

Versão final apresentada em 7 de abril de 2008

Aprovado em 30 de junho de 2008
18. Bernardis KC, Marchi SON. Sucção não-nutritiva em recém-nascidos a termo e pré-termo: um estudo descritivo comparativo. Pró-Fono. 1998; 10: 8-15.

19. Quintella T, Silva AA, Botelho MIMR. Distúrbios da deglutição (e aspiração) na infância. In: Furkin AM, Santini CS, editores. Disfagias orofaríngeas. Carapicuíba: Pró-fono; 1999. p. 61-96.

20. Polit DF, Hungler BP. Nursing research: principles and methods. 5. ed. Philadelphia: JB. Lippincot; 1995.

21. Riccio GMG, Sampaio LABN, Faria MFG, Caracciolo LT, Ribeiro FG, Cruz DM. Validação de instrumento de levantamento dados para formulação dos diagnósticos em enfermagem. Rev Soc Cardiol Estado São Paulo. 1995; 5 (3 Supl. A): 1-16.

22. Perroca MG. Sistema de classificação de pacientes: construção e validação de um instrumento. [dissertação]. São Paulo: Escola de Enfermagem da Universidade de São Paulo; 1996. 